
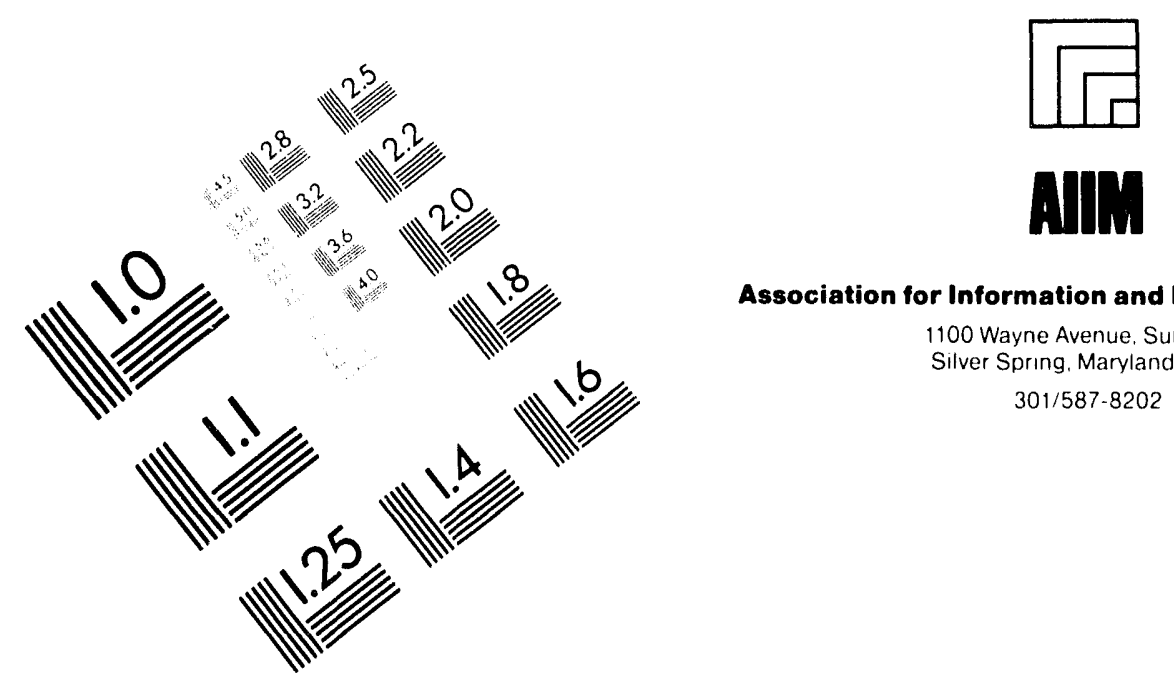

Association for Information and Image Management 1100 Wayne Avenue. Suite 1100 Silver Spring. Maryland 20910 301/587-8202

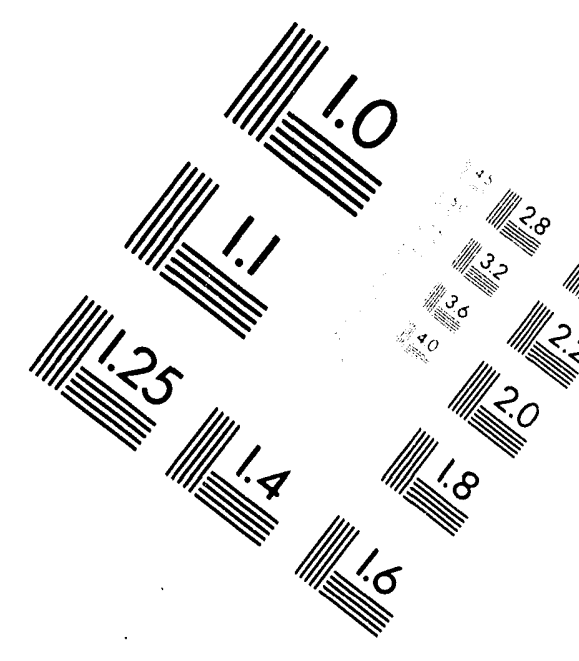

\title{
Centimeter
}

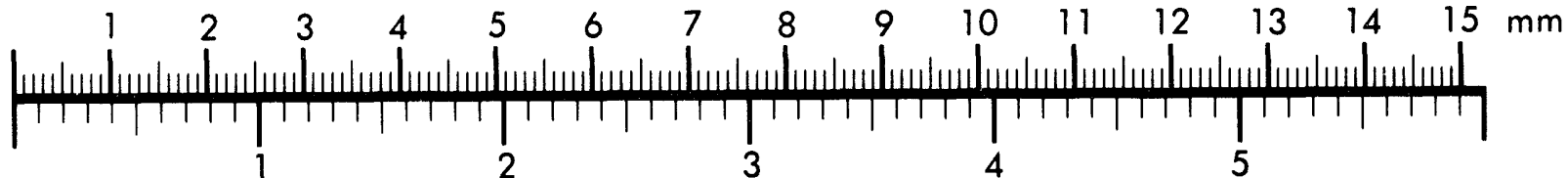
Inches
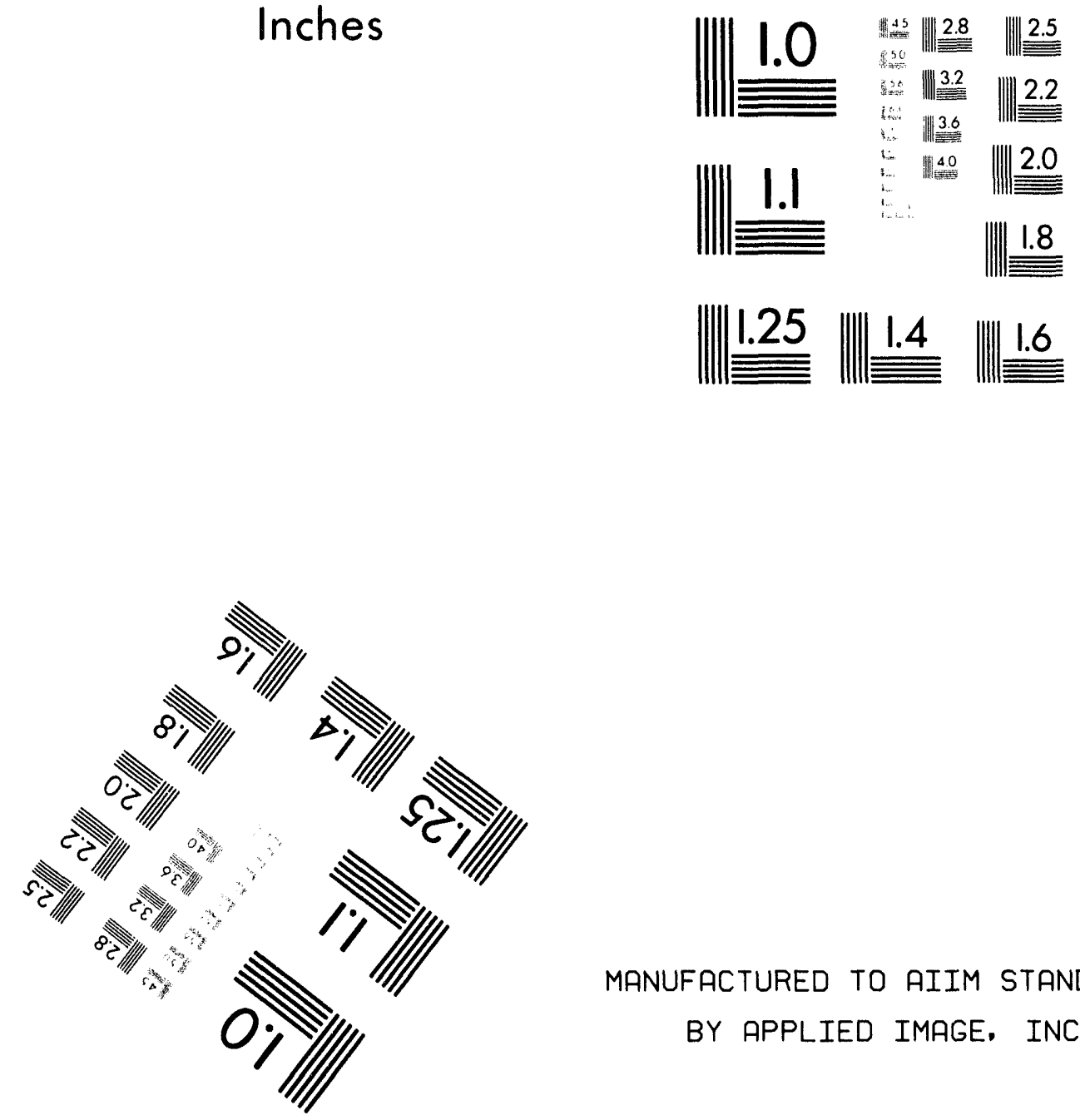

MANUFACTURED TO AIIM STANDARDS

BY APPLIED IMAGE. INC.

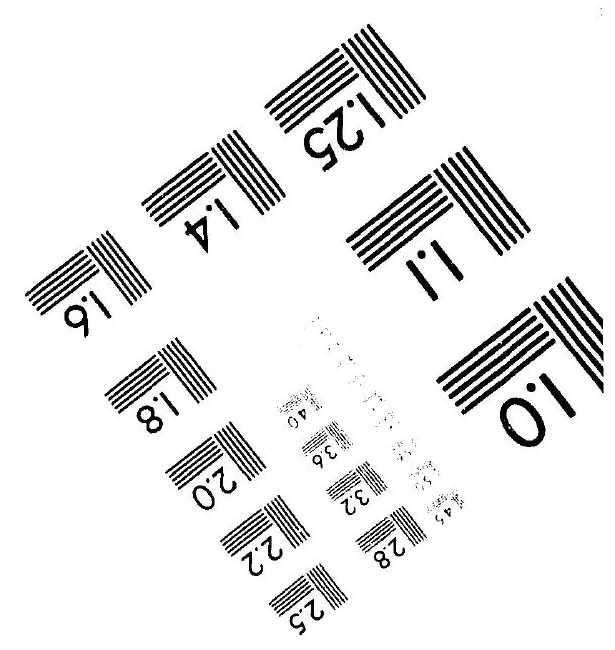



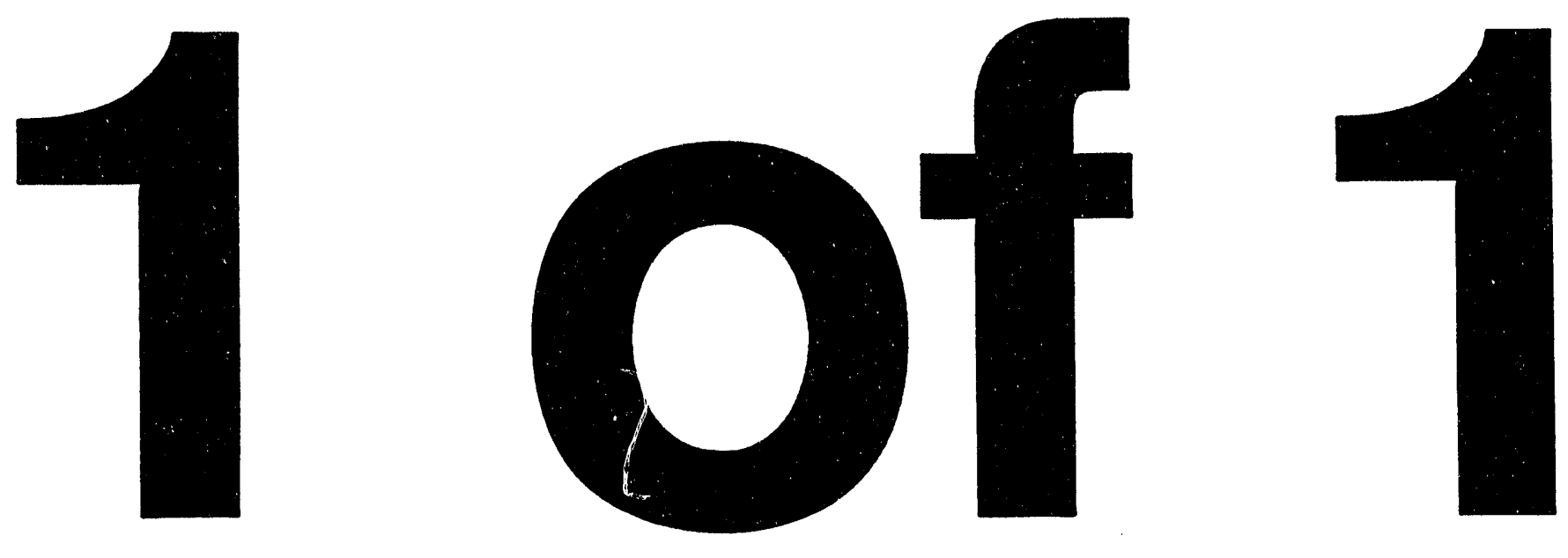


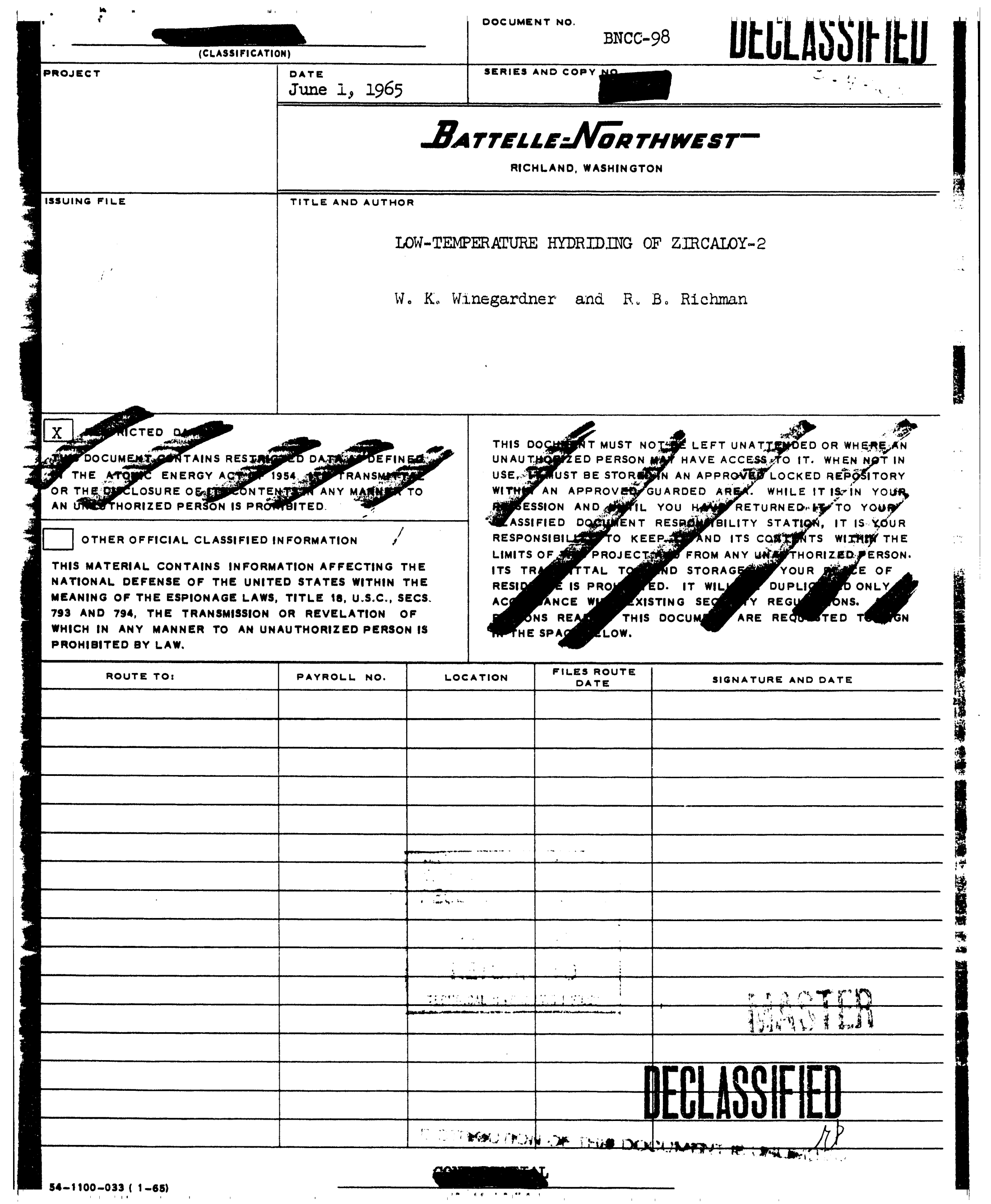



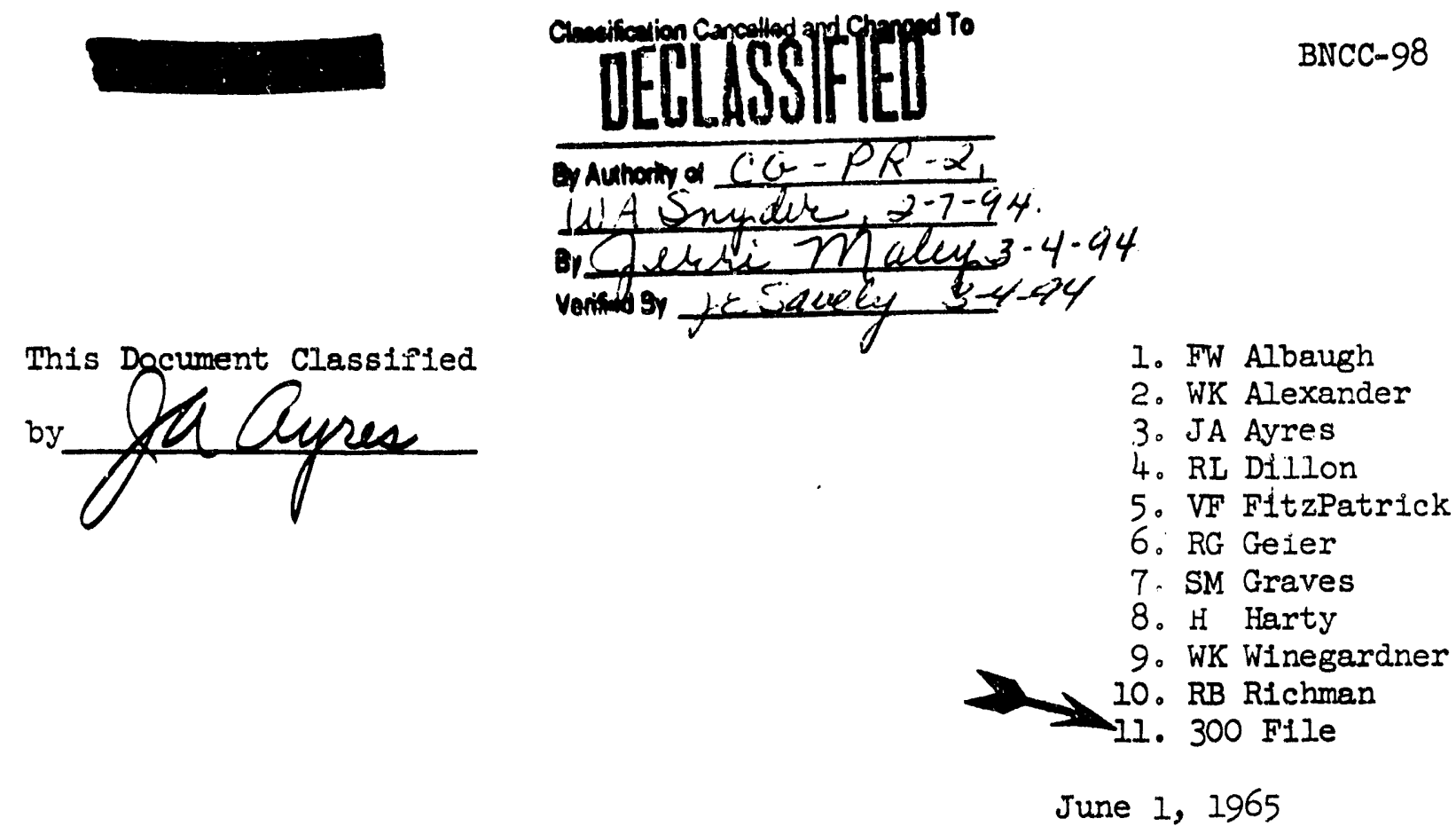

S. M. Graves

Process and Reactor Development

Research and Engineering Section

Irradiation Processing Department

General Electric Company

\section{LOW-TEMPERATURE HYDRIDING OF ZIRCALOY-2}

This letter is written to describe our approach to the problem of hydriding of zircaloy tubes in the IPD Reactors and to summarize the results we have obtained to date.

It is hypothesized that fretting may be an important factor in the hydriding effect. The aluminum spacers at the downstream end of the tube are under heavy load. Vibration could cause slight relative movement at the Al-Zr interface at high frequency under heavy load. This could result in true fretting attack, where aluminum oxide abrades the Zircaloy surface, removing the protective $\mathrm{ZrO}_{2}$ coating and exposing bare metaliic surfaces. Hydrogen, arising from the corrosion of aluminum, would be avallable for hydriding the zirconium. Fretting is a wear-corrosion process; any other process which promotes wear, e.g., charge-discharge, may also contribute to the hydriding. A second factor, which may act in conjunction with or be completely dependent of the mechanisms described above, is the slight possibility of the use of a fluoride decontaminant which could attack the Zircaloy and cause hydriding.

Experiments we have scheduled to investigate low temperature hydriding include:

a. Exposures of pretreated coupons to low-temperature water in both in-reactor and out-of-reactor facilities.

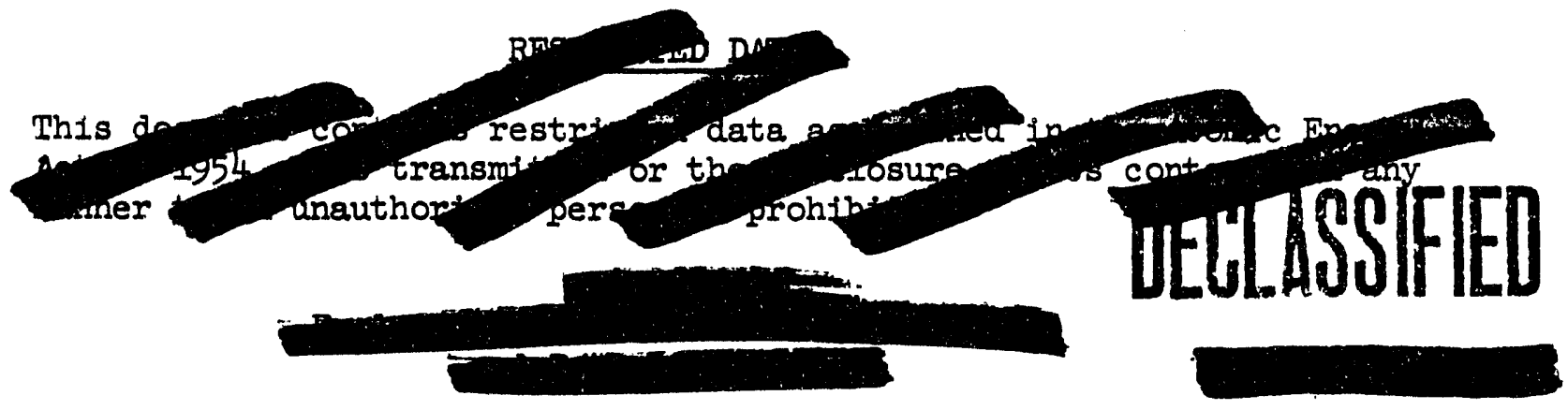


$\therefore$

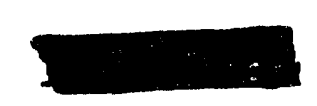

b. Dynamic wear-corrosion (fretting) tests using a Zircaloy - aluminum interface.

c. Dynamic, wear-corrosion tests using other materials to determine if hydriding can be prevented by using spacers of material other than aluminum. Candidate spacer materials include carbon steel, stain: less steel, Zircaloy.

d. Studies to evaluate the use of corrosion probes to detect hydriding.

Initial results from the above tests consist of the analysis of the hydride content of pretreated or sensitized Zircaloy-2 coupons which were exposed for 360 hours in an out-of-reactor facility (TF-20). The pretreatment associated with the various coupons is tabulated below.

Pretreatment

Polishing

Etching

Etching, Scratching and Smearing with AI Etching, Scratching and Smearing with Al, Fluoride Paste Treatment (b)

Etching, Fluoride Paste Treatment(b)
No. of Coupons

1

1

1

(a) Only one of these coupons exposed in TF-20.

(b) Fluoride paste treatment consists of coupon contact with a decontaminating agent containing $\mathrm{NH}_{4} \mathrm{~F}$ at about $100 \mathrm{C}$, followed by rinsing.

Both of the coupons with a pretreatment of scratching and smearing with aluminum, and one of the two polished samples, showed local hydride cases about one mil thick after TF-20 exposure in $6.6 \mathrm{pH}$ process water. No hydride case was visible on any of the remaining samples.

Hydride cases were revealed by etching and thickness was measured by metallographic examination at 250x. Examination of the "polished" coupon showed an essentialiy continuous, one-mil surface layer, which was estimated to be at least $30 \%$ Zirconium Hydride. Iocal surface areas of virtually 100\% Zirconium Hydride were present in coupons that had been pretreated by scratching and smearing with aluminum. Hydride areas on the scratcned coupons were about $1 \mathrm{mll}$ thick and 2 to $4 \mathrm{mlls}$ long. Vacuum analyses, on four central portions of each coupon, revealed hydride concentrations ranging from 9 to $32 \mathrm{ppm}$. The hydride concentration, as determined by vacuum analysis, was not significantly different on the three coupons with the hydride case from that found on coupons with no hydride case.

It should be noted that one of the two coupons which was scratched and smeared with aluminum was also pretreated with fluorlde; exposure of a third coupon, pretreated with fluoride but not smeared with aluminum, did not result in hydriding. It is currently believed that the hydriding of the two "smeared" coupons was due solely to the fact that the coupons were 
smeared with aluminum. The reason why one of the two polished coupons was hydrided is unknown. Additional pretreated coupons have received approximately 1200 hours exposure in TF-20 and are now being measured for hydride.

Initial test resultis suggest that dynamic wear-corrosion tests, currently in progress, will also result in the hydriding of Zircaloy. In these tests Zircaloy and aluminum surfaces are held in intimate contact by a nearnormal force and the assembly is vibrated; relative movement arising from the vibration can repeatedly damage the zirconium oxide layer ard continuously deposit (smear) aluminum on the Zircaloy.

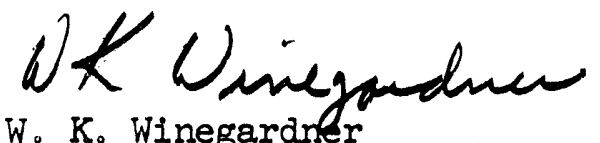

W. K. Winegardnh

Coolant Systems Development Unit

Reactor Engineering Section

REACTOR AND MATERIALS TECHNOLOGY DEPARTMENT

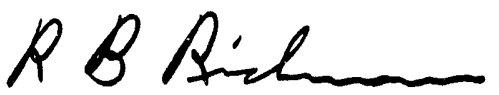

R. B. Richman

Coolant Systems Development Unit

Reactor Engineering Section

REACTOR AND MATERIALS TECHNOLOGY DEPARTMEINT

WKW : RBR:mf 

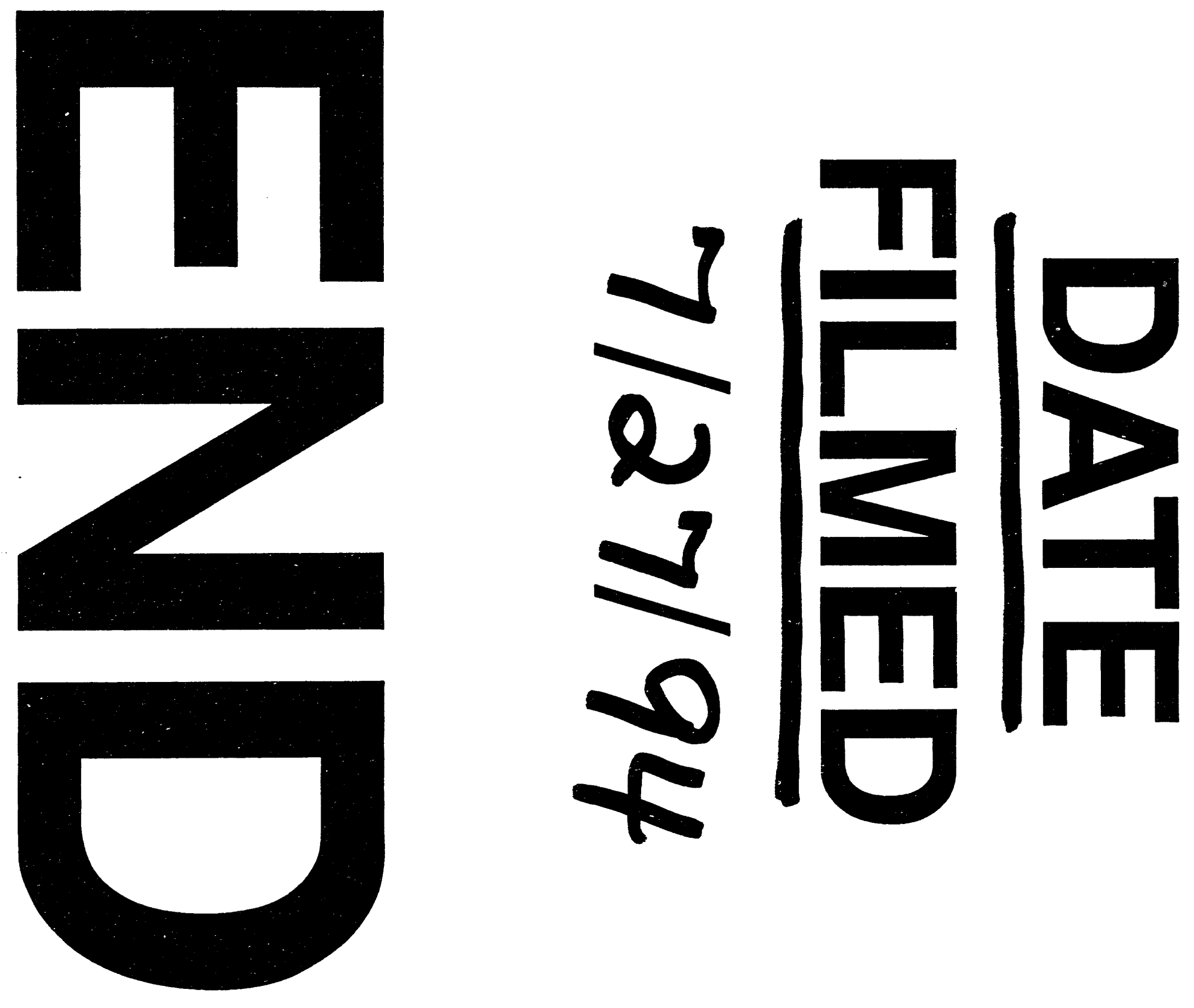


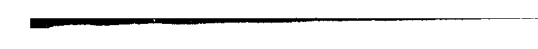

